Check for updates

Cite this: Nanoscale Adv., 2019, 1, 2553

\title{
Parameters affecting the synthesis of carbon dots for quantitation of copper ions $\uparrow$
}

\author{
Yu-Syuan Lin,,$^{a}$ Yaling Lin, $\$^{a}$ Arun Prakash Periasamy, ${ }^{a}$ Jinshun Cang ${ }^{b}$ \\ and Huan-Tsung Chang (D) *ac
}

A simple, eco-friendly, and low-cost electrochemical approach has been applied to the synthesis of carbon dots ( $\mathrm{C}$ dots) from histidine hydrochloride in the absence or presence of halides $(\mathrm{Cl}, \mathrm{Br}$, and $\mathrm{I}$ ) at various potentials up to $10 \mathrm{~V}$. The as-formed $\mathrm{C}$ dots refer to $\mathrm{C}$ dots, $\mathrm{Cl}-\mathrm{C}, \mathrm{Br}-\mathrm{C}$, and $\mathrm{I}-\mathrm{C}$ dots. The time-evolution UV-vis absorption and photoluminescence (PL) spectra provide more detailed information about the formation of $C$ dots. Upon increasing the reaction time from 1 to $120 \mathrm{~min}$, more and more $C$ dots are formed, leading to increased PL intensity. The halides play two important roles in determining the formation of $\mathrm{C}$ dots; controlling the reaction rate and surface states. When compared to chloride and bromide, iodide has a greater effect on varying surface states and inducing PL quenching through intersystem crossing. The $\mathrm{PL}$ intensities of the four types of $\mathrm{C}$ dots all decrease upon increasing $\mathrm{Cu}^{2+}, \mathrm{Hg}^{2+}$, and $\mathrm{Ag}^{+}$concentrations. In the presence of $0.8 \mathrm{mM} \mathrm{I}^{-}, \mathrm{I}-\mathrm{C}$ dots compared to $\mathrm{C}$ dots, $\mathrm{Cl}-\mathrm{C}$ dots, and $\mathrm{Br}-\mathrm{C}$ dots are slightly better for quantitation of $\mathrm{Cu}^{2+}$. Fourier transform infrared spectroscopy, cyclic voltammetry, electrochemical impedance spectroscopy, and $\mathrm{X}$-ray photoelectron spectroscopy results of $\mathrm{I}-\mathrm{C}$ dots reveal the interactions of $\mathrm{Cu}^{2+}$ with the surface ligands (imidazole and histidine). The I-C dot probe in the presence of $0.8 \mathrm{mM} \mathrm{I}^{-}$is selective toward $\mathrm{Cu}^{2+}$ over the tested metal ions such as $\mathrm{Hg}^{2+}$ and $\mathrm{Ag}^{+}$. The assay provides a limit of detection of $0.22 \mu \mathrm{M}$ for $\mathrm{Cu}^{2+}$ at a signal-to-noise ratio of 3 . Practicality of this probe has been validated by the analyses of tap, lake, and sea water samples, with negligible matrix effects.

Received 4th March 2019 Accepted 10th May 2019

DOI: 10.1039/c9na00137a

rsc.li/nanoscale-advances

\section{Introduction}

Photoluminescent nanomaterials such as carbon dots (C dots), quantum dots, nanoclusters, and gold nanodots have become interesting optical sensing materials for detecting various analytes. ${ }^{1-5}$ Among them, $\mathrm{C}$ dots are more biocompatible and stable against salt and photoirradiation induced photoluminescence (PL) quenching. Most $\mathrm{C}$ dots possess interesting excitation dependent PL properties; their emission undergoes a red shift upon increasing the excitation wavelength. ${ }^{6}$ Usually, their PL intensity decreases upon increasing the emission wavelength. ${ }^{7}$ The interesting PL properties of $\mathrm{C}$ dots are related to their core size, surface defects and ligands, oxidation state, and the number of conjugated $\pi$ electrons. ${ }^{1,8-14}$

Many approaches, including laser ablation, ultrasonication, direct heating, microwave-assisted heating, plasma treatment,

\footnotetext{
${ }^{a}$ Department of Chemistry, National Taiwan University, Taipei 10617, Taiwan. E-mail: changht@ntu.edu.tw

${ }^{b}$ Department of Chemical Engineering, Yancheng Institute of Industry Technology, Yancheng, Jiangsu 224005, China

'Department of Chemistry, Chung Yuan Christian University, Taoyuan City 32023, Taiwan

$\dagger$ Electronic supplementary information (ESI) available. See DOI: 10.1039/c9na00137a

\$ These authors contributed equally to this work.
}

hydrothermal routes, have been applied for the preparation of C dots from different precursors. ${ }^{15-21}$ Among them, the hydrothermal approach is the most popular, mainly because of its simplicity. ${ }^{6,21}$ It has been reported that $\mathrm{C}$ dots are formed through four steps i.e. condensation, polymerization, carbonization, and passivation. ${ }^{22-24}$ Various sources, including coffee powder, tea, and apple juice, have been used for the preparation of $\mathrm{C}$ dots through hydrothermal approaches. ${ }^{6,25-30}$ However, hydrothermal approaches require high energy and are usually limited to the preparation of few grams of $\mathrm{C}$ dots per batch.

Although the formation processes and optical properties of $\mathrm{C}$ dots have been suggested, ${ }^{22-24}$ strong evidence to support the suggestion/hypothesis is still needed. In this study, we applied our previously developed electrochemical approach to the preparation of $\mathrm{C}$ dots from histidine. ${ }^{31}$ We previously showed that control of the solution $\mathrm{pH}$ value is important for the electrochemical preparation of $\mathrm{C}$ dots from glycine. However, detailed information about the formation of $\mathrm{C}$ dots is missing. We in this study further tested several important factors for controlling the preparation of $\mathrm{C}$ dots from histidine, including electrolysis time, concentration of histidine, and species and concentration of salts (electrolytes). We measured the UV-vis absorption and PL spectra of $\mathrm{C}$ dots that had been prepared in alkaline solution at $10 \mathrm{~V}$ for different periods of time up to $120 \mathrm{~min}$. Through the obtained optical data, we provided more 
detailed information about the effect of halides on the formation of $\mathrm{C}$ dots. The $\mathrm{C}$ dots prepared in the presence of iodide $\left(\mathrm{I}^{-}\right)$ are selective and sensitive for quantitation of copper ions $\left(\mathrm{Cu}^{2+}\right)$ in the presence of $0.8 \mathrm{mM} \mathrm{NaI}$.

\section{Experimental}

\subsection{Materials}

L-Histidine hydrochloride monohydrate was purchased from TCI (Tokyo, Japan). Potassium nitrate $(>99.0 \%)$, silver nitrate $(>99.0 \%)$, and sodium chloride $(>99.0 \%)$ were purchased from Sigma-Aldrich (St. Louis, MO, USA). Copper nitrate trihydrate (>99.0\%), lead nitrate (>99.0\%), and sodium bromide (99.5\%) were purchased from Acros (Morris Plains, NJ, USA). Magnesium nitrate hexahydrate $(>98.0 \%)$ and sodium iodide $(>99.0 \%)$ were procured from SHOWA (Tokyo, Japan). Cobalt chloride $(97.0 \%)$, iron chloride $(98.0 \%)$, and mercury chloride $(>98.0 \%)$ were obtained from Alfa Aesar (Heysham, England). Calcium nitrate tetrahydrate $(>99.0 \%)$ and manganese chloride dehydrate $(>99.0 \%)$ were purchased from Merck (Kenilworth, NJ, USA). Monobasic, dibasic, and tribasic sodium salts of phosphate, phosphoric acid (85.0\%), sodium hydroxide (98.0\%), and zinc nitrate hexahydrate (>99.0\%) were obtained from J.T. Baker (Center Valley, PA, USA). Ultrapure water $(18.2 \mathrm{M} \Omega \mathrm{cm})$ from a Milli-Q system (Millipore, Billerica, MA, USA) was used to prepare all solutions.

\subsection{Preparation of $\mathrm{C}$ dots}

A two-platinum-electrode electrochemical system was used for the synthesis of $\mathrm{C}$ dots. The length and diameter of the $\mathrm{Pt}$ electrode are 6 and $0.05 \mathrm{~cm}$, respectively. A single output direct current (DC) power supply (TP-1303C, Taipei, Taiwan) was used for the synthesis of $\mathrm{C}$ dots under a static potential (1 to $10 \mathrm{~V}$ ) between the two electrodes. Known amounts $(0.38-3.83 \mathrm{~g})$ of histidine hydrochloride were dissolved separately in $\mathrm{NaOH}$ solution $(1 \mathrm{M})$ to obtain final concentrations of $0.09-0.90 \mathrm{M}$, with a final $\mathrm{pH}$ value of 9.0 that was adjusted with $10 \mathrm{M} \mathrm{HCl}$ or $\mathrm{NaOH}$. To study the effect of halides on the formation of $\mathrm{C}$ dots from histidine, aqueous solutions of $\mathrm{NaCl}(0-2.34 \mathrm{~g}), \mathrm{NaBr}(2.06$ $\mathrm{g})$, or NaI ( $3.00 \mathrm{~g})$ were added to the histidine solutions $(20 \mathrm{~mL})$. Aliquots $(10 \mu \mathrm{L})$ of the solutions after being subjected to electrolysis for various periods of time (1-120 min) were taken out for spectrochemical measurement. For quantitation of $\mathrm{Cu}^{2+}$ ions, the $\mathrm{C}$ dots that had been prepared at $10 \mathrm{~V}$ for $120 \mathrm{~min}$ and had been left undisturbed at ambient temperature $\left(25^{\circ} \mathrm{C}\right)$ for two days were used. This solution was then filtered through a $0.22 \mu \mathrm{m}$ membrane to remove large particles, and was then subjected to dialysis against pure water through a membrane $(\mathrm{MWCO}=100-500 \mathrm{D})$ for $24 \mathrm{~h}$. For simplicity, C dots prepared in the presence of $\mathrm{Cl}^{-}, \mathrm{Br}^{-}$, and $\mathrm{I}^{-}$are denoted as $\mathrm{Cl}-\mathrm{C}, \mathrm{Br}-\mathrm{C}$, and I-C dots, respectively. Their concentrations are presented as $1 \times$ for simplicity.

\subsection{Characterization}

Aqueous solutions of four different types of $\mathrm{C}$ dots were subjected to PL measurements using a microplate fluorometer
(Synergy 4 Multi-Mode Microplate Reader) from BioTek instruments (Winooski, VT, USA). Their PL decay curves were recorded using a FluoTime 300 system from PicoQuant (Berlin, Germany) with a diode laser emitting at $375 \mathrm{~nm}$ as the light source. A Synergy H1 multi-mode monochromatic spectrophotometer from BioTek instruments (Winooski, VT, USA) was used to measure their UV-vis absorption spectra. The Fourier transform infrared (FTIR) spectra of histidine and C dots were recorded using a Varian 640 FTIR spectrophotometer from Varian (Palo Alto, CA, USA). The transmission electron microscopy (TEM) and high-resolution transmission electron microscopy (HRTEM) images of the $\mathrm{C}$ dots were acquired using an $\mathrm{H}^{-}$ 7100 TEM from Hitachi (Tokyo, Japan) and a JSM-1200EX II HRTEM from JEOL (Tokyo, Japan), respectively. The X-ray photoelectron spectroscopy (XPS) measurements were conducted using a K-Alpha X-ray photo electron spectrometer system from Thermo (Waltham, MA, USA). The binding energy values of $\mathrm{C}$ dots were calibrated using the C1s signal at $284.6 \mathrm{eV}$. Their Raman spectra were acquired using an Olympus BX51 microscope and a Nicolet Almega XR dispersive Raman spectrometer from Thermo (Waltham, MA, USA) with a $10 \mathrm{~mW}$ laser emitting at a $780 \mathrm{~nm}$ peak wavelength, using the Raman peak of Si wafer $\left(520 \mathrm{~cm}^{-1}\right)$ as a standard. Cyclic voltammetry (CV) curves of phosphate buffer $(20 \mathrm{mM}, \mathrm{pH} 3.0)$ without and with C dots $(200 \mu \mathrm{L})$ and metal ions $(200 \mu \mathrm{M})$ were recorded using a CHI 760D electrochemical work station from $\mathrm{CH}$ instruments (Austin, TX, USA). A glassy carbon electrode, saturated $\mathrm{Ag} / \mathrm{Ag} \mathrm{Cl}$, and Pt wire were used as the working, reference, and counter electrodes, respectively. Electrochemical impedance spectra (EIS) and the Nyquist plots of the glassy carbon electrode in the frequency range of 0.01 to $10000 \mathrm{~Hz}$ at an amplitude of $5 \mathrm{mV}$ were recorded using the $\mathrm{CHI} 760 \mathrm{D}$ electrochemical work station in $\mathrm{N}_{2}$ saturated phosphate buffer $(20 \mathrm{mM}, \mathrm{pH} 3.0)$ without and with $\mathrm{C}$ dots $(200 \mu \mathrm{L})$ and $\mathrm{Cu}^{2+}$ ions $(200 \mu \mathrm{M})$.

\subsection{Quantitation of $\mathrm{Cu}^{2+}$ ions}

Quantitation of $\mathrm{Cu}^{2+}$ ions $(0-50 \mu \mathrm{M})$ using C-dots $(0.001 \times$, final concentration) was conducted in phosphate buffer solutions (20 $\mathrm{mM}$ ) at $\mathrm{pH}$ values of 3.0 and 7.0. Linearity, limit of detection, and selectivity were investigated at $\mathrm{pH}$ 3.0. To obtain linearity for quantitation of $\mathrm{Cu}^{2+}$ ions, aliquots of $\mathrm{C}$ dots $(0.01 \times, 100 \mu \mathrm{L})$ were added to phosphate buffer solution $(25 \mathrm{mM}, \mathrm{pH} 3.0,800$ $\mu \mathrm{L})$ prior to the addition of $\mathrm{Cu}^{2+}$ ions $(0-500 \mu \mathrm{M}, 100 \mu \mathrm{L})$. The mixtures were equilibrated by shaking at ambient temperature for $60 \mathrm{~min}$, and their PL spectra were recorded when excited at $420 \mathrm{~nm}$. To test the selectivity, $\mathrm{C}$ dots $(0.1 \times, 100 \mu \mathrm{L})$ were added to phosphate buffer solution $(25 \mathrm{mM}, 800 \mu \mathrm{L})$. Various metal ions $\left(\mathrm{K}^{+}, \mathrm{Mg}^{2+}, \mathrm{Ca}^{2+}, \mathrm{Mn}^{2+}, \mathrm{Fe}^{3+}, \mathrm{Co}^{2+}, \mathrm{Cu}^{2+}, \mathrm{Zn}^{2+}, \mathrm{Pb}^{2+}, \mathrm{Hg}^{2+}\right.$, and $\mathrm{Ag}^{+} ; 1 \mathrm{mM}, 100 \mu \mathrm{L}$ ) were then added into the resulting solution. The mixtures were equilibrated by shaking at ambient temperature for $60 \mathrm{~min}$, and their PL spectra were recorded with an excitation wavelength of $420 \mathrm{~nm}$. This assay was validated by the analyses of lake and tap water samples that had been collected from the National Taiwan University campus, and the sea water sample that had been collected from Keelung coast (East China Sea; Taiwan). Each of the water samples was filtered 
through a $0.22 \mu \mathrm{m}$ membrane. Aliquots $(100 \mu \mathrm{L})$ of the real samples were spiked with various concentrations $(0.3-3 \mu \mathrm{M}$; final concentrations) of $\mathrm{Cu}^{2+}$ ions. Then, phosphate buffer (200 mM, pH 3.0, $100 \mu \mathrm{L}), \mathrm{C}$ dots $(0.01 \times, 100 \mu \mathrm{L})$, and ultrapure water were added subsequently to the spiked solutions, each with a final volume of $1.0 \mathrm{~mL}$. The mixtures were equilibrated by shaking at ambient temperature for $60 \mathrm{~min}$, and their PL spectra were recorded under excitation at $420 \mathrm{~nm}$.

\section{Result and discussion}

\subsection{Formation of $\mathrm{C}$ dots}

When applying a voltage greater than $1.31 \mathrm{~V}$, oxidation of histidine occurred on the Pt anode, in which the oxidized histidine was adsorbed onto the electrode through its terminal carboxyl group and secondary amino group. Most of the adsorbed molecules were then converted to form imidazoles. ${ }^{31,32}$ During the course of electrolysis, the solution $\mathrm{pH}$ value increased slightly as a result of the formation of $\mathrm{NH}_{3}$. The adsorbed imidazoles were converted to form $\mathrm{C}$ dots through a process of polymerization, carbonization and passivation. ${ }^{32}$ The production yield of $\mathrm{C}$ dots prepared from amino acids through a simple electrochemical approach under alkaline conditions is usually higher than that under acidic conditions. ${ }^{31}$ The yields of $\mathrm{C}$ dots, $\mathrm{Cl}-\mathrm{C}$ dots, $\mathrm{Br}-\mathrm{C}$ dots, and $\mathrm{I}-\mathrm{C}$ dots are 5.1, $12.3,15.6$ and $33.8 \%$, respectively. The yield of $\mathrm{C}$ dots is lower than that of the other three dots, mainly because they were prepared in the solution containing lower concentration of electrolyte. The yield of $\mathrm{I}-\mathrm{C}$ dots is the highest, mainly because $\mathrm{I}^{-}$is a stronger leaving group than $\mathrm{Br}^{-}$and $\mathrm{Cl}^{-}$, leading to higher reaction efficiency.

\subsection{Effect of applied voltage}

Applied voltage affects the electrolysis rate and thus the formation of $\mathrm{C}$ dots. At an applied voltage $<1.31 \mathrm{~V},{ }^{33} \mathrm{C}$-dots were not formed, mainly because the oxidation of histidine did not occur. At a constant electrolysis time ( $3 \mathrm{~min}$ ), the PL intensity of the solution increases upon increasing the applied voltage from 1 to $10 \mathrm{~V}$ as shown in Fig. 1A. Interestingly, the PL profiles are all similar, revealing that the applied voltage is unlikely to affect the structure of C-dots. The result reveals that more $\mathrm{C}$ dots were formed when applying a higher voltage for the same reaction time. Considering reaction speed and PL intensity, we selected $10 \mathrm{~V}$ for the preparation of $\mathrm{C}$ dots hereafter. Since the amount of heat and bubbles generated increased upon increasing the voltage, a voltage greater than $10 \mathrm{~V}$ is not suggested unless a cooling system is applied.

\subsection{Effect of histidine concentration and $\mathrm{pH}$ value}

Fig. 1B shows the PL spectra of $\mathrm{C}$ dots prepared from different concentrations of histidine $(0.09-0.90 \mathrm{M})$ at $\mathrm{pH} 9.0$ and $10 \mathrm{~V}$ for $120 \mathrm{~min}$. The PL intensity at $505 \mathrm{~nm}$ increases upon increasing the concentration of histidine up to $0.63 \mathrm{M}$. Upon further increasing the histidine concentration, the PL intensity decreases, mainly because through intermolecular attractions some unreacted histidine molecules formed aggregates and then adsorbed onto the surfaces of $\mathrm{C}$ dots, leading to aggregation of $\mathrm{C}$ dots. At the optimal histidine concentration $(0.63 \mathrm{M})$, we tested the effect of $\mathrm{pH}(3.0-9.0)$ on the formation of $\mathrm{C}$ dots. Fig. 1C shows that the PL intensity increases upon increasing the $\mathrm{pH}$ value from 3.0 to 9.0. Under acidic conditions ( $\mathrm{pH} \sim 3.0$ ), the protonated imidazole ring interacts weakly with the $\mathrm{Pt}$ anode surface, leading to poor efficiency of oxidation, polymerization, and carbonization. Upon increasing the $\mathrm{pH}$ value (e.g. $\mathrm{pH} \sim 5.0$ ), the interaction of histidine with the Pt electrode increases, thus $\mathrm{C}$ dots are formed quickly, leading to higher PL than that when synthesized at $\mathrm{pH}$ 3.0. More $\mathrm{C}$ dots are formed and PL further increases upon increasing the $\mathrm{pH}$ value from 5.0-7.0, simply because the interaction of the adsorbed molecule with the Pt electrode is stronger as a result of increased dissociation degree of its carboxylic acid group. ${ }^{34}$ At $\mathrm{pH} 9.0$, the PL intensity reaches its maximum. The anodic generation of oxygen/or hydroxyl ions accelerates the electrochemical oxidation/or polymerization of the adsorbed molecules, leading to the formation of $\mathrm{C}$ dots with more emissive traps and higher $\mathrm{PL}$ intensity. ${ }^{35}$ Upon further increasing the $\mathrm{pH}$ value, the amount of $\mathrm{C}$ dots formed increases slightly. Since it is difficult to prepare a solution with a similar composition to that at lower $\mathrm{pH}$ values, synthesis of $\mathrm{C}$ dots at $\mathrm{pH}>9.0$ was not conducted.

\subsection{Effect of sodium halides}

It has been reported that the addition of sodium halides into amino acid solution enhances its electrochemical oxidation rates due to increased conductivity. ${ }^{36}$ We thus investigated the effects of $\mathrm{NaCl}(0-2.0 \mathrm{M})$ on the formation of $\mathrm{C}$ dots under optimal conditions ( $0.63 \mathrm{M}$ histidine and $\mathrm{pH} 9.0$ ). Fig. 1D shows that the PL intensity of Cl-C dots increases upon increasing the $\mathrm{NaCl}$ concentration up to $1 \mathrm{M}$, mainly because of increased reaction rates. At $\mathrm{NaCl}$ concentrations greater than $1 \mathrm{M}$, histidine molecules aggregated as evidenced by the formation of a white solid product. Thus $1 \mathrm{M} \mathrm{NaCl}$ was found to be optimal for the preparation of $\mathrm{C}$ dots. Under similar synthesis conditions, $\mathrm{Br}-\mathrm{C}$ dots and $\mathrm{I}-\mathrm{C}$ dots were prepared for comparison of their physicochemical and spectrochemical properties with those of $\mathrm{Cl}-\mathrm{C}$ dots and $\mathrm{C}$ dots. Fig. $\mathrm{S} 1 \uparrow$ shows the TEM images of $\mathrm{C}$ dots, $\mathrm{Cl}-\mathrm{C}$ dots, Br-C dots and, I-C dots. All of the $\mathrm{X}-\mathrm{C}$ dots were prepared under similar conditions (similar ionic strengths). By counting 100 of the four types of $\mathrm{C}$ dots, their average sizes were determined to be $3.2 \pm 0.6,3.9 \pm 0.9,3.8 \pm$ 0.6 , and $4.9 \pm 0.7 \mathrm{~nm}$, respectively. The HRTEM images displayed in the insets show that each of them has lattices with a $d$ spacing of $0.31 \mathrm{~nm}$ which are consistent with the (002) diffraction planes of $\mathrm{sp}^{2}$ graphitic carbon. The FTIR spectra (Fig. S2†) were recorded to identify the functional groups on the surfaces of the four types of C dots. The peaks at 2962, 1640, 1462 and $1150 \mathrm{~cm}^{-1}$ were assigned to $-\mathrm{CH}_{2}-$, amide $\mathrm{I} / \mathrm{C}=\mathrm{O}$, amide III/C-N, and $\mathrm{C}-\mathrm{O}$ stretching vibrations, respectively. The broad bands at around $3320 \mathrm{~cm}^{-1}$ suggest the existence of functional groups such as $-\mathrm{COOH},-\mathrm{OH},-\mathrm{NH}_{2}$, and $-\mathrm{NH}_{3}{ }^{+}$on the surface of all four types of $\mathrm{C}$ dots. ${ }^{37}$ The suggestion is supported by their high water dispersibility. The XPS spectra displayed in Fig. S3† show their C1s spectra, revealing the presence 
(A)

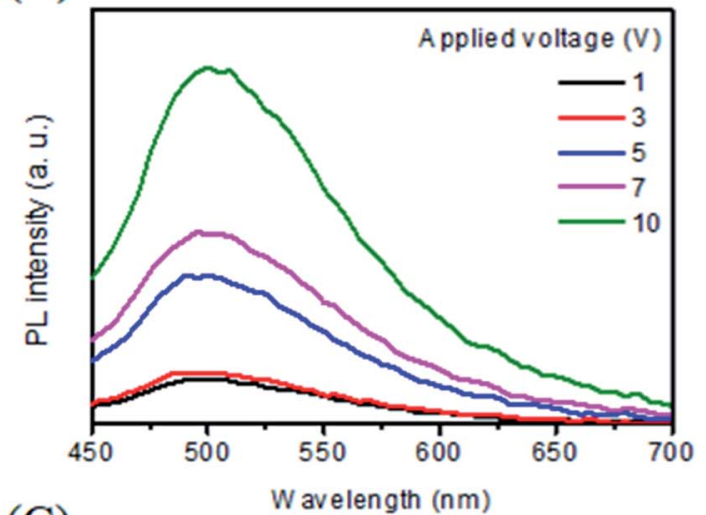

(C)

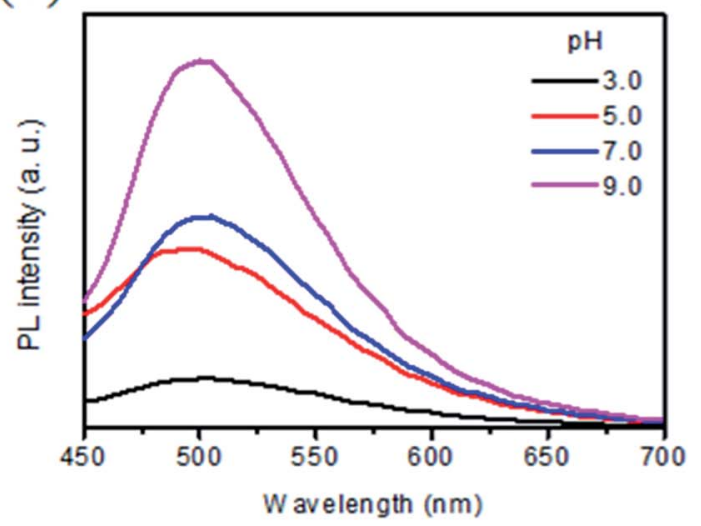

(B)

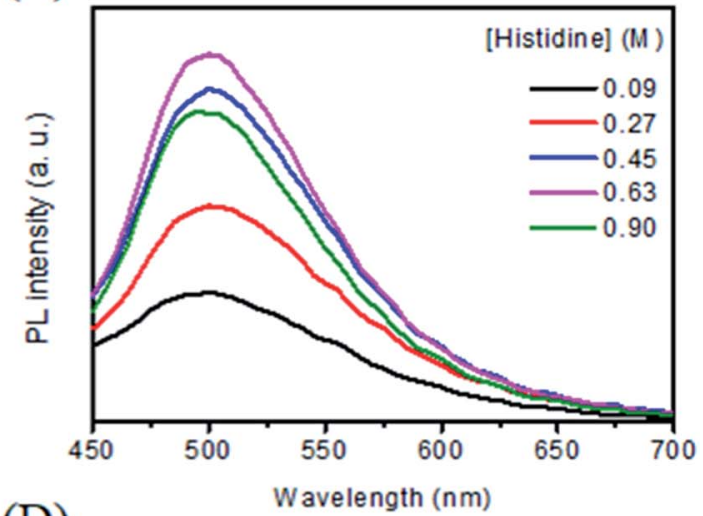

(D)

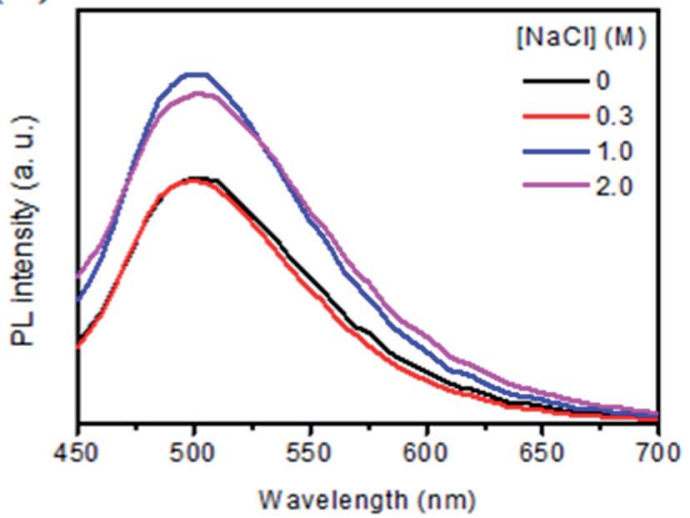

Fig. 1 Effects of (A) applied voltage, (B) histidine concentration, (C) $\mathrm{pH}$, and (D) $\mathrm{NaCl}$ concentration on the formation of $\mathrm{C}$ dots at $10 \mathrm{~V}$ for $2 \mathrm{~h}$. Excitation and emission wavelengths are $420 \mathrm{~nm}$ and $505 \mathrm{~nm}$, respectively. (A) $0.63 \mathrm{M}$ histidine at pH 9.0; (B) $1 \mathrm{M} \mathrm{NaCl}$ at pH 9.0; (C) $0.63 \mathrm{M}$ histidine and $1 \mathrm{M} \mathrm{NaCl}$; (D) $0.63 \mathrm{M}$ histidine at $\mathrm{pH} 9.0$.

of C-C (284.6 eV), C-I (285.2 eV), C-Br $(285.6 \mathrm{eV}), \mathrm{C}-\mathrm{N} / \mathrm{or} \mathrm{C}-\mathrm{O}$ $(286.0 \mathrm{eV}), \mathrm{C}-\mathrm{Cl}(286.6 \mathrm{eV}), \mathrm{C}=\mathrm{O}(286.8 \mathrm{eV})$, and $\mathrm{O}-\mathrm{C}=\mathrm{O}(287.8$ eV) bonds. ${ }^{38,39}$ Each of their N1s spectra shows four peaks at $398.1 \mathrm{eV}, 399.1 \mathrm{eV}, 399.8 \mathrm{eV}$ and $400.6 \mathrm{eV}$, which are attributed to pyridinic $\mathrm{N}$, pyrrolic $\mathrm{N}$, graphitic $\mathrm{N}$, and $\mathrm{N}-\mathrm{H}$, respectively. ${ }^{40}$ The deconvoluted C1s and N1s spectra support the presence of ring structures and the formation of $\mathrm{C}$ dots. Table $\mathrm{S} 1 \dagger$ lists the elemental compositions of the as-prepared $\mathrm{C}$ dots. Note that the $\mathrm{Br}-\mathrm{C}$ dots and I-C dots have higher oxygen content than the rest, indicating their greater surface passivation. The Raman spectra of the four types of $\mathrm{C}$ dots displayed in Fig. $\mathrm{S} 3 \dagger$ show the characteristic D- and G-bands at $1311 \mathrm{~cm}^{-1}$ and $1531 \mathrm{~cm}^{-1}$, which are attributed to the first-order scattering of the $E_{2 \mathrm{~g}}$ vibration mode in the graphite sheets and the structural defects, respectively. ${ }^{41}$ The peak at $1420 \mathrm{~cm}^{-1}$ is attributed to the carboxylate groups $\left(\mathrm{COO}^{-}\right){ }^{31}$ The D-band to G-band ratio $\left(I_{\mathrm{D}} / I_{\mathrm{G}}\right)$ of the four types of $\mathrm{C}$ dots decreases in the order of I-C dots $(0.98)>\mathrm{Br}-\mathrm{C}$ dots (0.96) > C dots (0.94) > Cl-C dots (0.90), showing that $\mathrm{I}-\mathrm{C}$ dots possess the highest density of defects. The result suggests that the halides affect the surface reconstruction processes and defects differently. ${ }^{42}$

Fig. 2A-C show the effect of sodium halides on the PL of $\mathrm{C}$ dots at different excitation wavelengths. As shown in Fig. 2A, C dots prepared in the absence and presence of $1 \mathrm{M} \mathrm{NaCl}$ upon excitation at $280 \mathrm{~nm}$ all exhibit one sharp peak at $330 \mathrm{~nm}$ and two broad peaks at 445 and $505 \mathrm{~nm}$. The sharp peak at $330 \mathrm{~nm}$ is attributed to strong emission from the $\pi-\pi^{*}$ transitions in the core. $^{43}$ The two broad peaks are attributed mainly to strong emissive contribution from the surface states. The PL intensities of $\mathrm{Cl}-\mathrm{C}$ dots at 445 and $505 \mathrm{~nm}$ are higher than the intensities of those prepared in the absence of $\mathrm{NaCl}$. Increased $\mathrm{NaCl}$ concentration greatly enhanced the oxidation rate of histidine, leading to the formation of more strong emissive surface states and thus high PL intensity. Unlike for $\mathrm{Cl}-\mathrm{C}$ dots, the peak at $330 \mathrm{~nm}$ for $\mathrm{Br}-\mathrm{C}$ dots or I-C dots was quenched significantly due to the inner effect, greater specific adsorption capacity and greater covalent character of $\mathrm{Br}^{-} / \mathrm{I}^{-}$than $\mathrm{Cl}^{-} .{ }^{44} \mathrm{Br}-\mathrm{C}$ and $\mathrm{I}-\mathrm{C}$ dots both show two peaks at 445 and $505 \mathrm{~nm}$, revealing the existence of emissive surface states. Although $\mathrm{I}^{-}$has a greater effect on the surface state, the PL intensities of I-C dots at the two peaks are weaker than those of $\mathrm{Cl}-\mathrm{C}$ and $\mathrm{Br}-\mathrm{C}$ dots, mainly because it induces greater PL quenching through intersystem crossing. The quenching efficiency of $\mathrm{C}$ dots at $505 \mathrm{~nm}$ induced by $1 \mathrm{mM} \mathrm{NaI}$ is $43.9 \%$, which supports our reasoning. As shown in Fig. 2B, upon excitation at $360 \mathrm{~nm}$, two emission peaks at 445 and $490 \mathrm{~nm}$ were observed for all the four types of $\mathrm{C}$ dots. Their $\mathrm{PL}$ intensities decrease in the order of $\mathrm{Cl}-\mathrm{C}$ dots $>\mathrm{Br}-\mathrm{C}$ dots $>\mathrm{C}$ dots $>$ I-C dots because of strong intersystem crossing (heavyatom effect). As shown in Fig. 2C, upon excitation at $420 \mathrm{~nm}$, an emission peak at $505 \mathrm{~nm}$ was observed, with a decreasing 
(A)

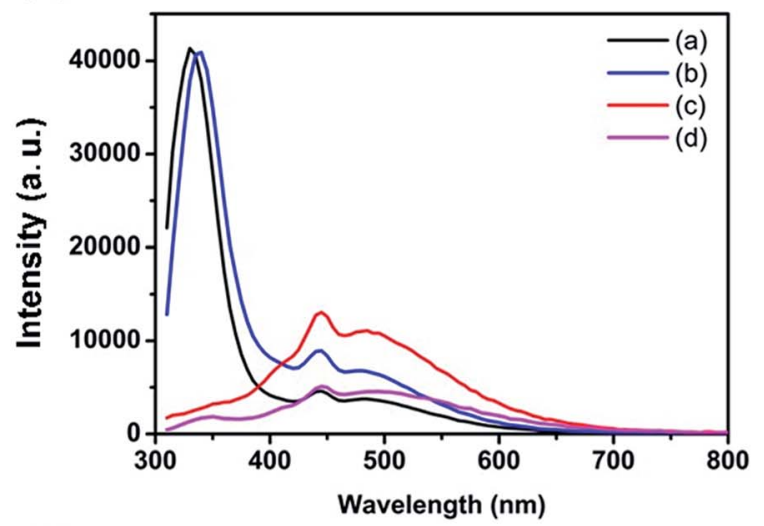

(C)

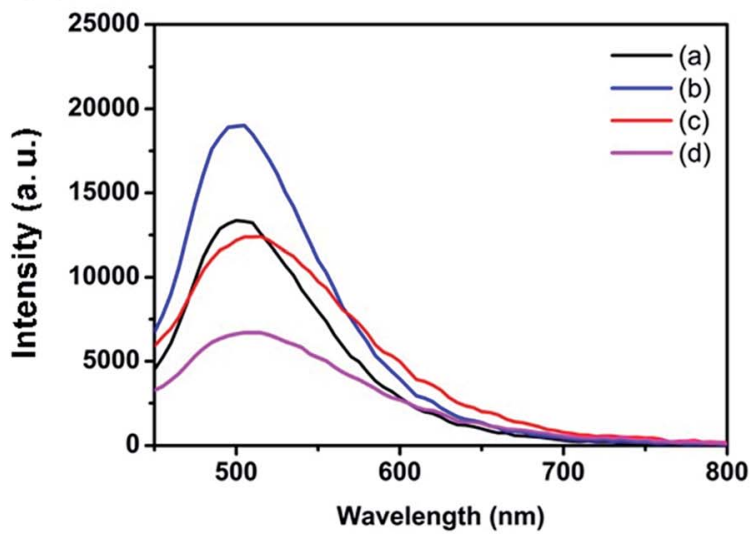

(B)

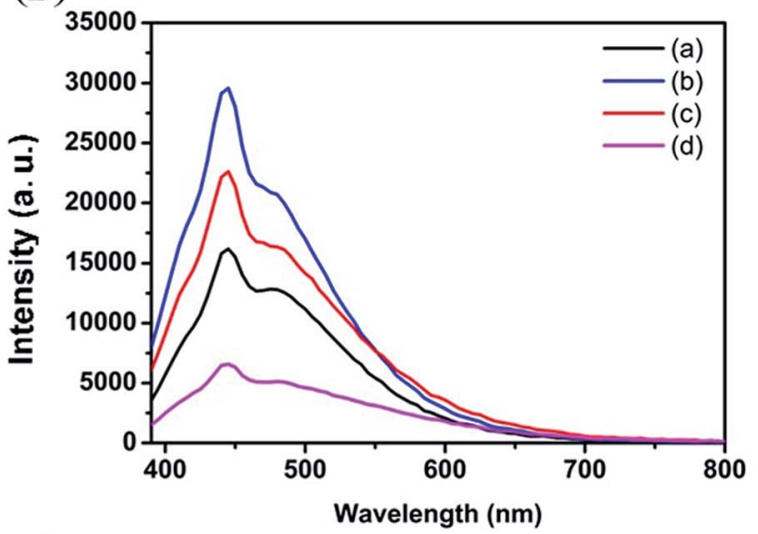

(D)

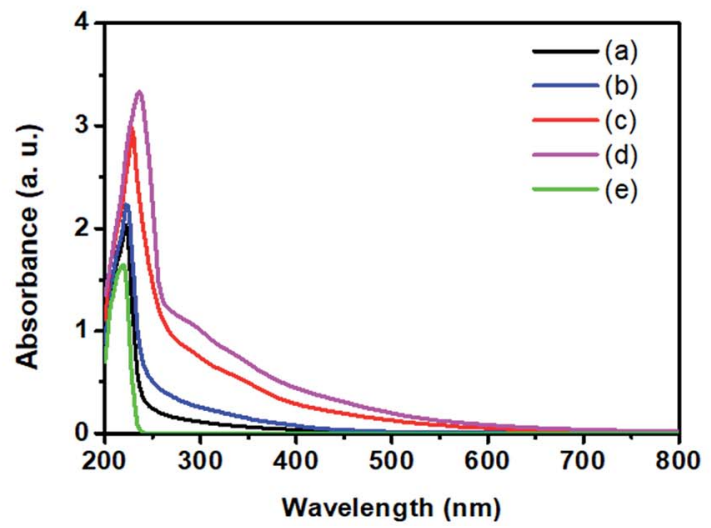

Fig. 2 Effect of sodium halides on the formation of $\mathrm{C}$ dots from $0.63 \mathrm{M}$ histidine solution at $\mathrm{pH} 9.0 \mathrm{with} /$ without $1 \mathrm{M} \mathrm{NaX}$ at $10 \mathrm{~V}$ for $2 \mathrm{~h}$. PL spectra ( $A-C$ ) and UV-vis absorption spectra (D). PL spectra of $C$ dots (a), $C l-C$ dots (b), Br-C dots (c), and I-C dots (d) at excitation wavelengths of (A) 280, (B) 360, and (C) $420 \mathrm{~nm}$. UV-vis absorption spectra of $\mathrm{C}$ dots (a), $\mathrm{Cl}-\mathrm{C}$ dots (b), Br-C dots (c), I-C dots (d) and histidine (e).

order of PL intensity: $\mathrm{Cl}-\mathrm{C}$ dots $>\mathrm{C}$ dots $>$ Br-C dots > I-C dots. The differential PL increasing/decreasing orders at various excitation wavelengths are mainly because the three halides have stronger effects on the surface emission than on the core emission. Fig. 2D shows the absorption spectra of all four tested $\mathrm{C}$ dot solutions and histidine hydrochloride solution. A sharp peak at $220 \mathrm{~nm}$ for histidine hydrochloride solution is assigned to its imidazole ring. ${ }^{45}$ The peak at $220 \mathrm{~nm}$ for $\mathrm{Br}-\mathrm{C}$ dots and I-C dots undergoes a red shift, mainly due to the absorption of the two halides. The broad absorption over the wavelength range from 300 to $400 \mathrm{~nm}$ is attributed to the $\mathrm{n}-\pi^{*}$ transition of the $\mathrm{C}=\mathrm{O}$ bond and the $\pi-\pi^{*}$ transition of the conjugated $\mathrm{C}=\mathrm{C}$ bond. ${ }^{24}$

\subsection{Effect of reaction time}

To provide more detailed information about the formation of $\mathrm{C}$ dots, we investigated the effect of reaction time on the formation of the four types of $\mathrm{C}$ dots. Fig. 3 shows the time-dependent PL intensities of all four types of $\mathrm{C}$ dots when excited at different wavelengths. As shown in Fig. 3A, upon excitation at $280 \mathrm{~nm}$, the PL of C dots at $330 \mathrm{~nm}$ increases gradually and reaches a plateau at around $50 \mathrm{~min}$. Meanwhile the $\mathrm{PL}$ of $\mathrm{Cl}-\mathrm{C}$ dots does not change significantly for the first 20 min period. Instead, it increases gradually and reaches a plateau at $50 \mathrm{~min}$. In both cases, the PL decreases slightly after $50 \mathrm{~min}$ and becomes stable after $120 \mathrm{~min}$. The results suggest that $\mathrm{Cl}^{-}$suppresses the core emission when its content in the $\mathrm{Cl}-\mathrm{C}$ dots is high. Upon increasing the reaction time, the amount of $\mathrm{C}$ dots increases, leading to lower density of adsorbed $\mathrm{Cl}^{-}$on the surface of each $\mathrm{C}$ dot. Because the emission at $330 \mathrm{~nm}$ is small in the $\mathrm{Br}-\mathrm{C}$ and I-C dots, the effects of $\mathrm{Br}^{-}$and $\mathrm{I}^{-}$on their time-evolution PL are hard to observe. Fig. 3B shows the comparison of the PL intensities of the four types of $\mathrm{C}$ dots at $445 \mathrm{~nm}$. Besides the PL of I-C dots, the PL intensities from the other three all increased gradually upon increasing the reaction time, revealing that more surface states are formed. For I-C dots, the PL increases gradually and reaches a plateau at around $8 \mathrm{~min}$, and then decreases before reaching a constant at around $30 \mathrm{~min}$, mainly because of the formation of $\mathrm{I}_{3}{ }^{-}$which has strong absorption bands centered separately near 280 and $350 \mathrm{~nm}$, leading to PL quenching of the $\mathrm{C}$ dots due to the inner filter effect. The PL intensities of $\mathrm{Cl}-\mathrm{C}$ dots, $\mathrm{Br}-\mathrm{C}$ dots and $\mathrm{I}-\mathrm{C}$ dots are all higher than those of $\mathrm{C}$ dots, supporting that the halides affect the surface emission and formation rate of $\mathrm{C}$ dots. Besides I-C dots, gradually increased PL intensities were found for the other C dots when excited at 360 or $420 \mathrm{~nm}$ (Fig. 3C-F). Because of stronger effects of iodide on the surface defects and intersystem 

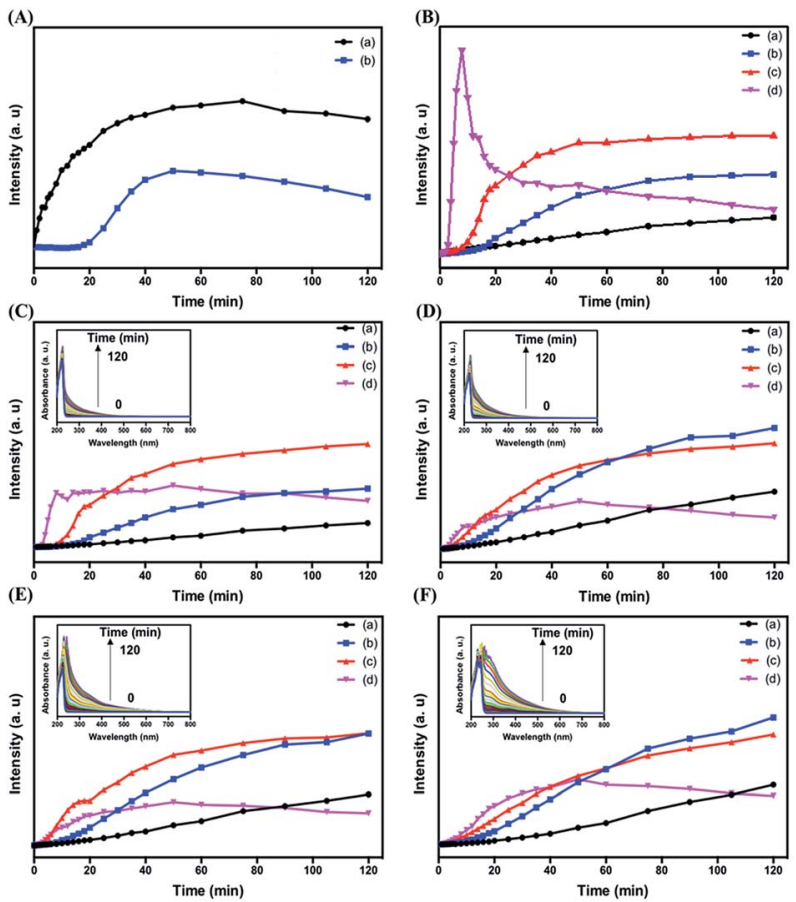

Fig. 3 Effect of reaction time on the PL intensity and UV-vis absorption spectra of $\mathrm{C}$ dots (a), $\mathrm{Cl}-\mathrm{C}$ dots (b), $\mathrm{Br}-\mathrm{C}$ dots (c), and I-C dots (d). The emission wavelengths are 330 (A), 445 (B), and $505 \mathrm{~nm}$ (C), respectively, when excited at $280 \mathrm{~nm}$. The emission wavelengths are 445 (D) and $490 \mathrm{~nm}$ (E), respectively, when excited at $360 \mathrm{~nm}$. The emission wavelength is $505 \mathrm{~nm}$ (F) when excited at $420 \mathrm{~nm}$. Insets in (C) - (F) are their corresponding UV-vis absorption spectra. All C dots were prepared at $10 \mathrm{~V}$ from $0.63 \mathrm{M}$ histidine solutions at $\mathrm{pH} 9.0$ with/ without $1 \mathrm{M} \mathrm{NaX}$.

crossing, the PL intensities of I-C dots decrease once they reach their maxima. Interestingly, all the three types of $\mathrm{C}$ dots prepared in the presence of sodium halides show detectable PL within 1 min electrolysis when excited at 360 or $420 \mathrm{~nm}$ (Fig. 3C-F). Also displayed in the insets of Fig. 3C-F are their time-dependent UV-vis absorption spectra. The sharp peak at $220 \mathrm{~nm}$ for each of the four types of $\mathrm{C}$ dots is assigned to that of the imidazole ring. ${ }^{45}$ Upon increasing the electrolysis time, the peak of $\mathrm{Br}-\mathrm{C}$ dots or $\mathrm{I}-\mathrm{C}$ dots at $220 \mathrm{~nm}$ undergoes a red shift due to increased absorption of $\mathrm{Br}_{2}$ or $\mathrm{I}_{2}$ as a result of increases in their formation amounts. The absorbance values over 300 to $400 \mathrm{~nm}$ increase upon increasing the reaction time, mainly because of gradual increases in the formation of $\mathrm{C}$ dots. Table 1 reveals negligible differences in the PL lifetimes (excitation wavelength/emission wavelength: $375 / 440 \mathrm{~nm}$ ) of C dots, Cl-C dots, $\mathrm{Br}-\mathrm{C}$ dots and $\mathrm{I}-\mathrm{C}$ dots regardless of the reaction times. The lifetime data support that iodide induced greater intersystem crossing. Besides I-C dots, the other three types of C dots obtained after $60 \mathrm{~min}$ have slightly longer lifetimes, mainly because of increases in their surface oxidation with oxygen.

\subsection{Formation routes}

Scheme 1 summarizes the formation of $\mathrm{C}$ dots from histidine at pH 9.0. After adsorption of histidine onto the anodic Pt electrode, histidine undergoes electrochemical oxidation to form
Table 1 PL lifetimes of four different types of $C$ dots determined at different time periods of electrolysis

\begin{tabular}{lllll}
\hline Nanomaterials & $\tau_{1 \text { min }}(\mathrm{ns})$ & $\tau_{30 \min }(\mathrm{ns})$ & $\tau_{60 \min }(\mathrm{ns})$ & $\tau_{120 \mathrm{~min}}(\mathrm{~ns})$ \\
\hline C dots & 5.57 & 4.92 & 4.83 & 5.05 \\
Cl-C dots & 4.58 & 4.71 & 4.45 & 4.54 \\
Br-C dots & 4.51 & 4.89 & 4.72 & 4.84 \\
I-C dots & 4.29 & 4.40 & 4.01 & 3.91
\end{tabular}

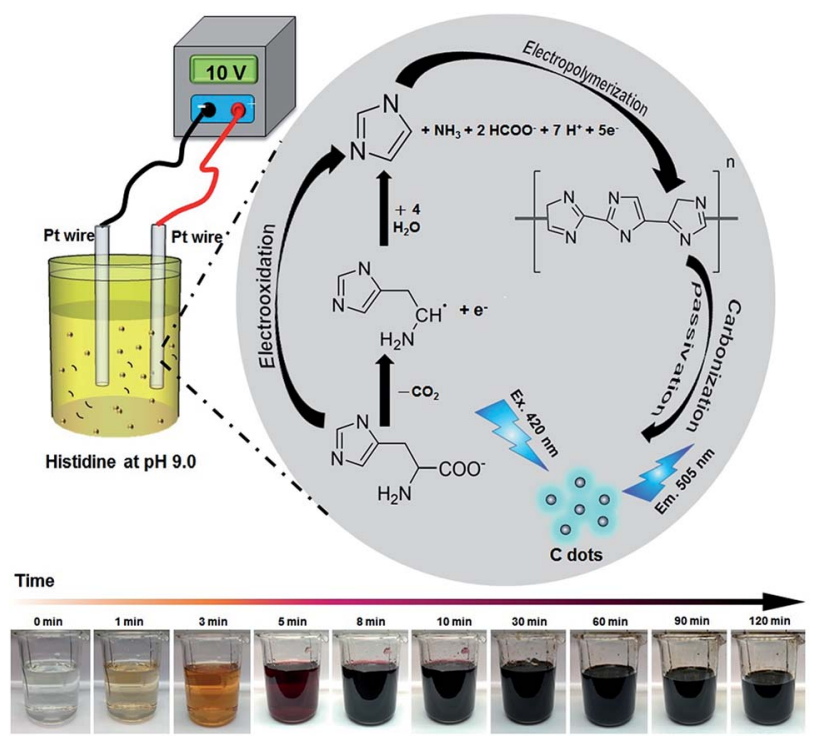

Scheme 1 Schematic representation of preparation of $C$ dots from histidine hydrochloride through an electrochemical route.

imidazole. Subsequently, the adsorbed imidazole goes through a process of polymerization, carbonization, and passivation to form C dots. As shown in Scheme 1 the solution color changes can be easily observed by the naked eye. The solution becomes darker upon increasing the reaction time, mainly because greater amounts of C-dots and larger aggregates (particles) of C dots are formed. Oxidation also occurs, leading to changes in their surface states. Addition of the halides to the reaction solution increases the conductivity and thus the electrolysis rate. In addition, the halides also induce the formation of greater surface defects. Their different nucleophilic substitution rates, specific adsorption capacity, and migration/ diffusion rates are also responsible for the formation of different $\mathrm{C}$ dots. ${ }^{46}$

\subsection{Sensitivity and selectivity}

To test the analytical application of the four types of C-dots, their stability in aqueous solutions at different $\mathrm{pH}$ values (3.0-11.0) was tested. As displayed in Fig. S5A, $\uparrow$ they are all stable in the tested $\mathrm{pH}$ region. The main reason for choosing the excitation/emission wavelengths of $420 / 505 \mathrm{~nm}$ is because the optical properties are related to the surface defects of the $\mathrm{C}$ dots and are expected to be more sensitive to an environmental change. Fig. S5B $\uparrow$ shows their high salt tolerance, being stable 
up to $3 \mathrm{M} \mathrm{NaCl}$. The results reveal their potential in analytical applications. Because histidine has high specificity towards $\mathrm{Cu}^{2+}$ (formation constant $K=2.34 \times 10^{10}$ at $\left.\mathrm{pH} 4.0\right),{ }^{47}$ we used the as-prepared $\mathrm{C}$ dots to detect $\mathrm{Cu}^{2+}$ ions. $\mathrm{Cu}^{2+}$ plays important roles in many biological functions, while at high concentrations also potentially causes some diseases such as gastrointestinal disorders and liver/kidney damage. ${ }^{48-50}$ Although the sensitivity for the detection of $\mathrm{Cu}^{2+}$ is slightly higher at $\mathrm{pH} 7.0$ than at 3.0, mainly because $\mathrm{Cu}^{2+}$ ions interact more strongly with the adsorbed histidine and the surface functional groups such as amino and carboxylate, interference from $\mathrm{Zn}^{2+}$ ions is severe at $\mathrm{pH}>3.0$. In addition, formation of metal oxides is another disadvantage. On the other hand, poor sensitivity and lower stability of $\mathrm{C}$ dots at $\mathrm{pH}<3.0$ are disadvantageous.

To evaluate the selectivity of the four types of $\mathrm{C}$ dots toward $\mathrm{Cu}^{2+}$ at $\mathrm{pH} 3.0$, we determined their relative $\mathrm{PL}$ intensity $\left[\left(I_{\mathrm{F}}-I_{\mathrm{Fo}}\right) / I_{\mathrm{Fo}}\right]$ at $505 \mathrm{~nm}$ in the presence of different metal ions when excited at a wavelength of $420 \mathrm{~nm}$. Fig. S6† shows the selectivity of all four types of tested $\mathrm{C}$ dots toward various metal ions at a concentration of $100 \mu \mathrm{M}$. $\mathrm{Cu}^{2+}, \mathrm{Hg}^{2+}$, and $\mathrm{Ag}^{+}$ all induced significant PL quenching of the four types of $\mathrm{C}$ dots. To mask the interferences from $\mathrm{Hg}^{2+}$ and $\mathrm{Ag}^{+}$ions, $\mathrm{NaI}$ was added. The solubility product $\left(K_{\mathrm{sp}}\right)$ values of $\mathrm{Hg}_{2} \mathrm{I}_{2}$ and AgI are $4.6 \times 10^{-29}$ and $8.3 \times 10^{-17}$, respectively, which are much smaller than that $\left(1.0 \times 10^{-12}\right)$ of CuI. To minimize interference from $\mathrm{Ni}^{2+}$, in addition to $\mathrm{NaI}$, citric acid that can form stronger complexes with $\mathrm{Ni}^{2+}$ than with $\mathrm{Cu}^{2+}$ was added. ${ }^{51}$ In the presence of $0.8 \mathrm{mM} \mathrm{NaI}$ and $1 \mathrm{mM}$ citric acid, the $\mathrm{I}-\mathrm{C}$ dot probe provides high selectivity toward $\mathrm{Cu}^{2+}$ ions $(100 \mu \mathrm{M})$ over the potential interfering metal ions $(100 \mu \mathrm{M})$ as shown in Fig. 4A. We note that the other three types of $\mathrm{C}$ dots also can be used for selective detection of $\mathrm{Cu}^{2+}$ ions, with slightly higher interference from some potential interfering species such as $\mathrm{Fe}^{3+}$. Hereafter, we only discuss quantitation of $\mathrm{Cu}^{2+}$ using $\mathrm{I}-\mathrm{C}$ dots.
Fig. 4B shows that the relative PL intensity of $\mathrm{I}-\mathrm{C}$ dots decreases upon increasing $\mathrm{Cu}^{2+}$ ion concentration in the range of 0-50 $\mu \mathrm{M}$. The $\mathrm{Cu}^{2+}$ induced PL quenching is mainly through an electron transfer process. ${ }^{52}$ The quenching efficiencies of $\mathrm{C}$ dots and $\mathrm{I}-\mathrm{C}$ dots induced by $100 \mu \mathrm{M} \mathrm{Cu}^{2+}$ are $65.2 \%$ and $65.6 \%$, respectively, ruling out strong interaction of the surface iodides with $\mathrm{Cu}^{2+}$. The I-C dot probe exhibits linearity toward $\mathrm{Cu}^{2+}$ ions over the concentration range of $0.3-3 \mu \mathrm{M}\left(R^{2}=0.98\right)$, with a limit of detection (LOD) of $0.22 \mu \mathrm{M}$ at a signal-to-noise ratio of 3. The LOD is lower than the tolerance level $(20 \mu \mathrm{M})$ of $\mathrm{Cu}^{2+}$ ions in drinking water defined by the US Environmental Protection Agency (EPA). ${ }^{4}$ Table S $2 \uparrow$ lists the linear ranges and the LODs of different nanomaterial based probes toward the quantitation of $\mathrm{Cu}^{2+}$ ions, showing that a lower LOD is provided by the I-C dots than that by the rest. ${ }^{53-60}$ In addition, organic solvent is not required when applying this simple assay. Having high selectivity and a low LOD, the I-C dot probe holds great potential for the quantification of $\mathrm{Cu}^{2+}$ ions in real samples containing complex matrixes.

\subsection{Sensing mechanism}

To provide more information about the specificity of I-C dots toward $\mathrm{Cu}^{2+}$ ions, a simple and sensitive electrochemical tool (CV) was applied. A bare GCE exhibits a featureless CV curve over the potential range from -0.6 to $0.8 \mathrm{~V}$ in the presence of I-C dots $(1 \mathrm{~mL})$ as shown in Fig. S7A. $\dagger$ Faradaic or non-faradaic reactions did not occur even when CVs were recorded over a wide potential window $(-0.6-1.3 \mathrm{~V})$, revealing that the active binding sites did not contribute to the electron transfer or double layer capacitance. In a solution containing I-C dots and $\mathrm{Fe}^{3+}$ ions, oxidation or reduction peaks of $\mathrm{Fe}^{3+}$ ions were not detected. After spiking $\mathrm{Cu}^{2+}$ ions $(100 \mu \mathrm{M})$ into the solution, two reduction peaks at $c a$. -0.1 and $-0.31 \mathrm{~V}$ and one oxidation peak at ca. $0.1 \mathrm{~V}$ appeared. ${ }^{61}$ Peaks at -0.31 and $0.1 \mathrm{~V}$ are attributed to the reduction and oxidation of $\mathrm{Cu}$-histidine complexes,
(A)

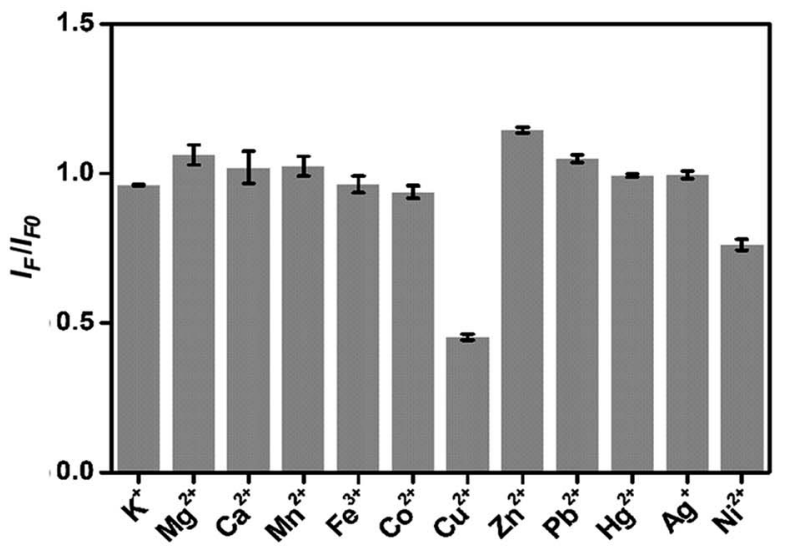

(B)

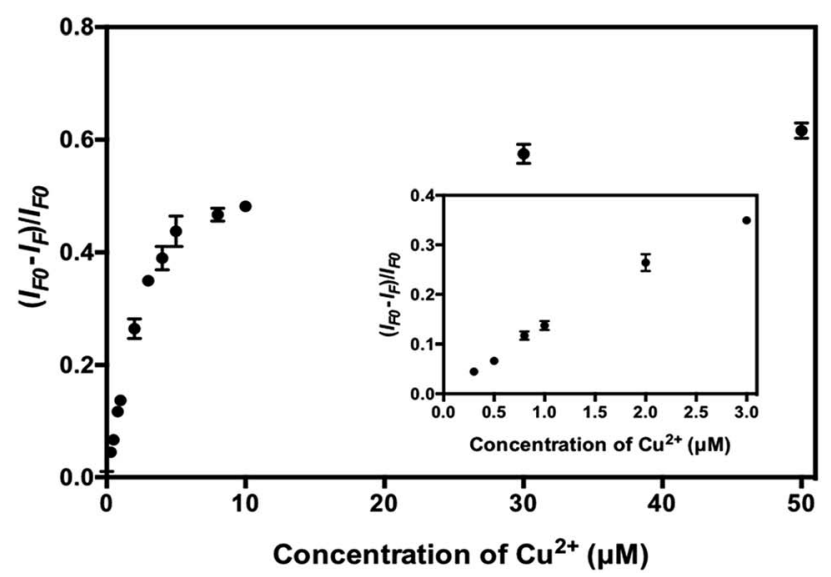

Fig. 4 Selectivity (A) and sensitivity (B) of $\mathrm{I}-\mathrm{C}$ dots towards $\mathrm{Cu}^{2+}$ ions $(100 \mu \mathrm{M})$ in phosphate buffer $(20 \mathrm{mM}, \mathrm{pH} 3.0) \mathrm{containing} 0.8 \mathrm{mM}$ Nal and $1 \mathrm{mM}$ citric acid. The concentrations of $\mathrm{I}-\mathrm{C}$ dots in $(\mathrm{A})$ and $(\mathrm{B})$ are $0.01 \times$ and $0.001 \times$, respectively. $I_{\mathrm{FO}}$ and $I_{\mathrm{F}}$ are the $\mathrm{PL}$ intensities of $\mathrm{I}-\mathrm{C}$ dots at $505 \mathrm{~nm}$ in the absence and presence of $\mathrm{Cu}^{2+}$, respectively, when excited at $420 \mathrm{~nm}$. The concentrations for the other metal ions are all $100 \mu \mathrm{M}$. $\mathrm{I}-\mathrm{C}$ dots were prepared from $0.63 \mathrm{M}$ histidine solution at $\mathrm{pH} 9.0$ containing $1 \mathrm{M} \mathrm{Nal}$ at $10 \mathrm{~V}$ for $2 \mathrm{~h}$. 
respectively. Upon increasing $\mathrm{Cu}^{2+}$ concentration, the reduction peaks shifted to more negative potentials, revealing that $\mathrm{Cu}^{2+}$ ions were reduced to metallic copper $\left(\mathrm{Cu}^{0}\right)$ at $c a$. $-0.1 \mathrm{~V}$. To identify the interfacial changes during the formation of the complex, EIS measurements were conducted. The Nyquist plot of a bare GCE recorded in the presence of I-C dots with $\mathrm{N}_{2}$ purging is displayed in Fig. S7B. $\uparrow$ The bare GCE exhibits a small arc in the high frequency region due to strong adsorption of I-C dots on the electrode surface. The arc diameter becomes smaller in the presence of $\mathrm{Cu}^{2+}$ as a result of improved charge transfer. CV and EIS results revealed the plausible binding sites of $\mathrm{Cu}^{2+}$ ions in $\mathrm{I}-\mathrm{C}$ dots and the reduction of $\mathrm{Cu}^{2+}$ ions to form metallic copper, supporting our proposed sensing mechanism. As shown in Table S1, $\uparrow$ the oxygen content of I-C dots increased significantly after reaction with $\mathrm{Cu}^{2+}$ ions. As depicted in Fig. S2, $\uparrow$ the characteristic absorption peaks at $1640 \mathrm{~cm}^{-1}$ and $1596 \mathrm{~cm}^{-1}$ disappeared after reaction with $\mathrm{Cu}^{2+}$ ions, revealing the oxidation of amide I groups on the surface of I-C dots. ${ }^{62}$ Two new bands at 1289 and $2383 \mathrm{~cm}^{-1}$ are ascribed to the $\mathrm{C}-\mathrm{O}$ and $\mathrm{CO}_{2}$ stretching vibrations, which revealed that the surface functional groups of I-C dots were oxidized. The $2 \mathrm{p}_{3 / 2}$ and $2 \mathrm{p}_{1 / 2}$ peaks at 932.3 and $952.1 \mathrm{eV}$ in the $\mathrm{Cu} 2 \mathrm{p}$ spectrum are attributed to the metallic copper, respectively (Fig. $\mathrm{S} 3 \dagger$ ). ${ }^{63}$ There is a small characteristic satellite peak around $942.0 \mathrm{eV}$ for $\mathrm{Cu} 2 \mathrm{p}_{3 / 2}$, which indicates that some unreacted copper ions were bound onto the surface of I-C dots. All these results confirm that the I-C dots were oxidized by the surface $\mathrm{Cu}^{2+}$ ions/complexes and metallic copper was formed on the surface of I-C dots.

\subsection{Real sample analysis}

Practicality of the I-C dot probe was validated through the determination of the concentrations of $\mathrm{Cu}^{2+}$ ions in various real samples, including tap water, lake water and sea water, using a standard addition method. Fig. $\mathrm{S} 8 \dagger$ shows good linearity $\left(R^{2}=\right.$ $0.98)$ of relative PL intensity $\left[\left(I_{\mathrm{Fo}}-I_{\mathrm{F}}\right) / I_{\mathrm{Fo}}\right]$ responses at $505 \mathrm{~nm}$ toward spiked $\mathrm{Cu}^{2+}$ ions over the concentration range from 0.3 to $3 \mu \mathrm{M}$. There was no obvious difference in the linearity and the slope among the three samples, revealing negligible matrix effects. Having high sensitivity and selectivity, this probe is useful for quantitation of $\mathrm{Cu}^{2+}$ ions in water samples.

\section{Conclusions}

A simple and cost-effective electrochemical approach was applied to prepare $\mathrm{C}$ dots from histidine under alkaline conditions, which allows one to gain more information about the formation of $\mathrm{C}$ dots. Upon increasing the reaction time, more $\mathrm{C}$ dots were formed. Because the formation speed of $\mathrm{C}$ dots increases upon increasing the electrolysis rate, larger amounts of C-dots can be prepared in a short period of time from precursors in high-conductivity media at a high voltage using a large electrode. When compared to hydrothermal routes, this electrochemical approach produces a much lower amount of large particles. Halides induce surface defects, leading to enhanced surface emission intensity, but they also cause PL quenching through intersystem crossing. Having high sensitivity and selectivity, the I-C dot probe holds great potential for quantitation of $\mathrm{Cu}^{2+}$ in complicated samples.

\section{Conflicts of interest}

There are no conflicts to declare.

\section{Acknowledgements}

This study was financially supported by the Ministry of Science and Technology of Taiwan (MOST) under contract 107-2113-M002-015-MY3. A. P. Periasamy is grateful to MOST for a postdoctoral fellowship under the contract number MOST 106-2811M-002-083. We thank Ms. S.-J. Ji and C.-Y. Chien of the Precious Instrument Center of NTU for their assistance in HRTEM analyses.

\section{References}

1 Z. X. Liu, B. B. Chen, M. L. Liu, H. Y. Zou and C. Z. Huang, Green Chem., 2017, 19, 1494-1498.

2 H. Jin, R. Gui, J. Gong and W. Huang, Biosens. Bioelectron., 2017, 92, 378-384.

3 W. Y. Chen, C. C. Huang, L. Y. Chen and H. T. Chang, Nanoscale, 2014, 6, 11078-11083.

4 G. Y. Lan, C. C. Huang and H. T. Chang, Chem. Commun., 2010, 46, 1257-1259.

5 J. Feng, W. J. Wang, X. Hai, Y. L. Yu and J. H. Wang, J. Mater. Chem. B, 2016, 4, 387-393.

6 P. C. Hsu, Z. Y. Shih, C. H. Lee and H. T. Chang, Green Chem., 2012, 14, 917-920.

7 H. Nie, M. Li, Q. Li, S. Liang, Y. Tan, L. Sheng, W. Shi and S. X. A. Zhang, Chem. Mater., 2014, 26, 3104-3112.

8 S. Liu, J. Tian, L. Wang, Y. Zhang, X. Qin, Y. Luo, A. M. Asiri, A. M. A. O. Al-Youbi and X. Sun, Adv. Mater., 2012, 24, 20372041.

9 X. Wang, K. Qu, B. Xu, J. Ren and X. Qu, J. Mater. Chem., 2011, 21, 2445-2450.

10 L. Ma, W. D. Xiang, H. H. Gao, J. Wang, Y. Ni and X. Liang, Dyes Pigm., 2016, 128, 1-7.

11 H. Li, X. He, Z. Kang, H. Huang, Y. Liu, J. Liu, S. Lian, C. H. A. Tsang, X. Yang and S. T. Lee, Angew. Chem., Int. Ed., 2010, 49, 4430-4434.

12 D. Pan, J. Zhang, Z. Li and M. Wu, Adv. Mater., 2010, 22, 734738.

13 G. E. LeCroy, F. Messina, A. Sciortino, C. E. Bunker, P. Wang, S. K. A. Fernando and Y. P. Sun, J. Phys. Chem. C, 2017, 121, 28180-28186.

14 V. Strauss, J. T. Margraf, C. Dolle, B. Butz, T. J. Nacken, J. Walter, W. Bauer, W. Peukert, E. Spiecker, T. Clark and D. M. Guldi, J. Am. Chem. Soc., 2014, 136, 17308-17316.

15 Y. P. Sun, B. Zhou, Y. Lin, W. Wang, K. A. S. Fernando, P. Pathak, M. J. Meziani, B. A. Harruff, X. Wang, H. Wang, P. G. Luo, H. Yang, M. E. Kose, B. Chen, L. M. Veca and S. Y. Xie, J. Am. Chem. Soc., 2006, 128, 7756-7757.

16 Q. L. Zhao, Z. L. Zhang, B. H. Huang, J. Peng, M. Zhang and D. W. Pang, Chem. Commun., 2008, 5116-5118. 
17 J. Niu and H. Gao, J. Lumin., 2009, 149, 159-162.

18 Z. Ma, H. Ming, H. Huang, Y. Liu and Z. Kang, New J. Chem., 2012, 36, 861-864.

19 V. N. Mehta, S. Jha, R. K. Singhal and S. K. Kailasa, New J. Chem., 2014, 38, 6152-6160.

20 S. Y. Park, C. Y. Lee, H. R. An, H. Kim, Y. C. Lee, E. C. Park, H. S. Chun, H. Y. Yang, S. H. Choi, H. S. Kim, K. S. Kang, H. G. Park, J. P. Kim, Y. Choi, J. Lee and H. U. Lee, Nanoscale, 2017, 9, 9210-9217.

21 P. C. Hsu and H. T. Chang, Chem. Commun., 2012, 48, 39843986.

22 A. B. Bourlinos, A. Stassinopoulos, D. Anglos, R. Zboril, V. Georgakilas and E. P. Giannelis, Chem. Mater., 2008, 20, 4539-4541.

23 S. Mitra, S. Chandra, T. Kundu, R. Banerjee, P. Pramanik and A. Goswami, RSC Adv., 2012, 2, 12129-12131.

24 X. Jia, J. Li and E. Wang, Nanoscale, 2012, 4, 5572-5575.

25 P. C. Hsu, P. C. Chen, C. M. Ou, H. Y. Chang and H. T. Chang, J. Mater. Chem. B, 2013, 1, 1774-1781.

26 C. L. Li, C. M. Ou, C. C. Huang, W. C. Wu, Y. P. Chen, T. E. Lin, L. C. Ho, C. W. Wang, C. C. Shih, H. C. Zhou, Y. C. Lee, W. F. Tzeng, T. J. Chiou, S. T. Chu, J. Cangm and H. T. Chang, J. Mater. Chem. B, 2014, 2, 4564-4571.

27 Y. S. Liu, Y. N. Zhao and Y. Y. Zhang, Sens. Actuators, B, 2014, 196, 647-652.

28 B. S. B. Kasibabu, S. L. D'souza, S. Jha, R. K. Singhal, H. Basu and S. K. Kailasa, Anal. Methods, 2015, 7, 2373-2378.

29 S. Sahu, B. Behera, T. K. Maiti and S. Mohapatra, Chem. Commun., 2012, 48, 8835-8837.

30 V. N. Mehta, S. Jha, H. Basu, R. K. Singhal and S. K. Kailasa, Sens. Actuators, B, 2015, 213, 434-443.

31 C. I. Wang, W. C. Wu, A. P. Periasamy and H. T. Chang, Green Chem., 2014, 16, 2509-2514.

32 K. Ogura, M. Kobayashi, M. Nakayama and Y. Miho, J. Electroanal. Chem., 1999, 463, 218-223.

33 D. M. Close and P. Wardman, J. Phys. Chem. A, 2018, 122, 439-445.

34 S. Li and M. Hong, J. Am. Chem. Soc., 2011, 133, 1534-1544.

35 N. L. Weinberg and H. R. Weinberg, Chem. Rev., 1968, 68, 449-523.

36 M. R. Thombare and G. S. Gokavi, J. Braz. Chem. Soc., 2014, 25, 1545-1551.

37 J. Jiang, Y. He, S. Li and H. Cui, Chem. Commun., 2012, 48, 9634-9636.

38 M. Patel, W. Feng, K. Savaram, M. R. Khoshi, R. Huang, J. Sun, E. Rabie, C. Flach, R. Mendelsohn, E. Garfunkel and H. He, Small, 2015, 11, 3358-3368.

39 X. L. Zhou, F. Solymosi, P. M. Blass, K. C. Cannon and J. M. White, Surf. Sci., 1989, 219, 294-316.
40 Z. Liu, Y. Yang, Z. Du, W. Xing, S. Komarneni, Z. Zhang, X. Gao and Z. Yan, Nanoscale Res. Lett., 2015, 10, 333-343.

41 Y. Q. Dong, L. S. Wan, J. H. Cai, Q. Q. Fang, Y. W. Chi and G. N. Chen, Sci. Rep., 2015, 5, 10037.

42 J. C. Charlier, Acc. Chem. Res., 2002, 35, 1063-1069.

43 J. Schneider, C. J. Reckmeier, Y. Xiong, M. V. Seckendorff, A. S. Andrei, S. Susha, P. Kasák and A. L. Rogach, J. Phys. Chem. C, 2017, 121, 2014-2022.

44 K. Ogura, J. $\mathrm{CO}_{2}$ Util., 2013, 1, 43-49.

45 L. J. Saidel, A. R. Goldfarb and S. Waldman, J. Biol. Chem., 1952, 197, 285-291.

46 H. Wang, B. C. W. Gu, D. W. Lee and J. S. Lee, Sci. Rep., 2017, 7, 43794 .

47 R. Leberman and B. R. Rabin, Trans. Faraday Soc., 1959, 55, 1660-1670.

48 D. G. Barceloux and D. Barceloux, J. Toxicol., Clin. Toxicol., 1999, 37(2), 217-230.

49 M. Olivares and R. Uauy, Am. J. Clin. Nutr., 1996, 63, 791S796S.

50 P. G. Georgopoulos, A. Roy, M. J. Yonone-Lioy, R. E. Opiekun and P. J. Lioy, J. Toxicol. Environ. Health, Part B, 2001, 4(4), 341-394.

51 O. Y. Zelenin, Russ. J. Coord. Chem., 2007, 33, 346-350.

52 J. Q. Tian, Q. Liu, A. M. Asiri, A. O. Al-Yubi and X. P. Sun, Anal. Chem., 2013, 85, 5595-5599.

53 A. Zhu, Q. Qu, X. Shao, B. Kong and Y. Tian, Angew. Chem., Int. Ed., 2012, 124, 7297-7301.

54 M. Koneswaran and R. Narayanaswamy, Sens. Actuators, B, 2009, 139, 104-109.

55 G. He, C. Liu, X. Liu, Q. Wang, A. Fan, S. Wang and X. Qian, PLoS One, 2017, 12, e0186994.

56 M. C. Rong, K. X. Zhang, Y. R. Wang and X. Chen, Chin. Chem. Lett., 2017, 28, 1119-1124.

57 C. Boonme, T. Noipa, T. Tuntulani and W. Ngeontae, Spectrochim. Acta, Part A, 2013, 169, 161-168.

58 X. F. Hou, F. Zeng, F. K. Du and S. Z. Wu, Nanotechnology, 2013, 24, 335502.

59 Y. Wang, W.-T. Wu, M.-B. Wu, H.-D. Sun, H. Xie, C. Hu, X.-Y. Wu and J.-H. Qiu, New Carbon Mater, 2015, 30, 550-559.

60 L. Zhao, H. Li, Y. Xu, H. Liu, T. Zhou, N. Huang, Y. Li and L. Ding, Anal. Bioanal. Chem., 2018, 410, 4301-4309.

61 Y. C. Weng and T. H. Cheng, Z. Naturforsch., 2011, 66, 279288.

62 G. Oza, K. Oza, S. Pandey, S. Shinde, A. Mewada, M. Thakur, M. Sharon and M. Sharon, J. Fluoresc., 2015, 25, 9-14.

63 Y. J. Lin, P. C. Chen, Z. Yuan, J. Y. Ma and H. T. Chang, Chem. Commun., 2015, 51, 11983-11986. 